\title{
Original
}

\section{Estudio digital radiográfico y densitométrico en mandíbulas de cerdos sometidos a osteotomía con alta y baja velocidad, con refrigeración líquida}

\author{
Lira Marcela Monti ${ }^{a *}$, Alvimar Lima de Castro ${ }^{b}$, Mário Jefferson Quirino Louzada ${ }^{c}$ \\ y Leda Maria Pescinini Salzedas ${ }^{d}$ \\ ${ }^{a}$ Maestro en Estomatología, Departamento de Odontología y Patología y Propedéutica Clínica, Facultad de Odontología, Araçatuba, UNESP, \\ Brasil. \\ bProfesor Doctor de Odontología, Departamento de Patología y Propedéutica Clínica, Facultad de Odontología, Araçatuba, UNESP, Brasil. \\ cProfesor Doctor de Biofísica, Departamento de Apoyo, Producción y Sanidad Animal, Facultad de Medicina Veterinaria de Araçatuba, \\ UNESP, Brasil. \\ dProfesora Doctora en Radiología, Departamento de Patología y Propedéutica Clínica, Facultad de Odontología de Araçatuba, UNESP, Brasil.
}

INFORMACIÓN DEL ARTÍCULO

Historia del artículo:

Recibido el 7 de mayo de 2010

Aceptado el 10 de noviembre de 2010

Palabras clave:

Cerdos;

Osteotomía;

Mejora de la imagen radiográfica;

Densidad

\section{R E S U M E N}

Se evaluó por medio de la radiografía digital y la densitometría, la influencia de un dispositivo de rotación para el corte en el proceso de curación del hueso después de osteotomías en mandíbulas de cerdos, a tiempos controlados. Se realizaron dos secciones transversales en la base de la mandíbula derecha, una con una alta velocidad de rotación y otra por la acción de baja velocidad, ambos con el líquido de irrigación. Tras los tiempos preestablecidos, los animales fueron sacrificados y sus mandíbulas retiradas para los estudios radiográficos y de densitometría radiológica con los sistemas digitales Cromox, Digora y ODR. En los períodos iniciales (7 y 28 días) el equivalente a la densitometría en milímetro de aluminio y la media de niveles de gris fueron más altos en la región de osteotomías hechas con alta rotación, y en los períodos finales (60 y 90 días) las mayores densitometrías fueron para osteotomías hechas con baja velocidad, lo que indica una mejor cicatrización final del hueso cuando se hace uso de la baja velocidad. El análisis cualitativo del proceso de reparación fue realizado por el ODR, lo que permitió la recopilación de imágenes digitales en color y en tres dimensiones, para la comparación del espesor del hueso con una cuña de aluminio, indicando que en los 28 días de curación del hueso, ya estaba evidente la completa reparación.

๔) 2010 SECOM. Publicado por Elsevier España, S.L. Todos los derechos reservados.

\footnotetext{
Trabajo de tesis presentado en el Campus de la Facultad de Odontología de Araçatuba, UNESP.

${ }^{*}$ Autora para correspondencia.

Correo electrónico: liramarcelam@yahoo.com.br (Lira Marcela Monti).
} 


\section{Digital and densitometric radiographic study in swine jaws subjected to osteotomy using high and low drilling speeds with liquid cooling}

Keywords:

Swine;

Osteotomy;

Radiographic image enhancement; Bone density

\begin{abstract}
A B S T R A C T
The influence of the type of rotary cutting instrument on bone repair after osteotomy in swine jaw, was evaluated using digital and densitometric radiographic examinations, at controlled times. Two cross-sectional dissections were made through the base of the right jaw, one using a high speed rotary instrument and the other using low speed, both with liquid cooling. After established periods the animals were sacrificed and their jaws removed for direct and indirect digital radiographic and densitometric studies using the CROMOX, DIGORA and ODR systems. In the initial periods (7 and 28 days) the bone density was higher in osteotomy areas performed with high rotation speeds, and in the final periods (60 and 90 days) the bone density was higher in the osteotomies performed with low rotation, indicating a better final bone repair with the use of low rotation. The qualitative analysis of the repair process was made by the ODR system which obtained three-dimensional and coloured digital images, which enable the bone thickness to be measured using an aluminium wedge. This showed that by twenty-eight days the bone repair was already apparently complete.
\end{abstract}

○ 2010 SECOM. Published by Elsevier España, S.L. All rights reserved.

\section{Introducción}

En el campo de la cirugía oral, las osteotomías son ampliamente utilizadas en la extracción de los dientes, en la enucleación de lesiones óseas y correcciones a través de gubia, sierras de hueso, cinceles, martillos, taladros y los instrumentos rotatorios, solos o asociados, que permiten una ejecución más rápida de la cirugía y una mejor comodidad del paciente ${ }^{1,2}$.

La mayoría de los estudios sobre los efectos de las osteotomías con diferentes instrumentos en la reparación ósea han sido evaluados histológicamente. Sin embargo, el uso de los recursos de radiología para el análisis cualitativo y cuantitativo ha ganado más atención con el advenimiento de la tecnología informática, especialmente la densitometría, que analiza cuantitativamente el contenido mineral óseo ${ }^{3,4}$ y consigue eludir la subjetividad individual en el análisis, la interpretación de imágenes radiográficas y las limitaciones visuales mediante la utilización de técnicas para medir la densidad óptica ${ }^{5,6}$. Así, este estudio tuvo como objetivo evaluar los procesos de reparación ósea en períodos controlados de osteotomías realizadas con taladros montados en velocidades altas y bajas y refrigeración líquida en las mandíbulas de los cerdos con el análisis cuantitativo de la densidad óptica de la imagen digital mediante el sistema Digora (Soredex) y el programa radiográfico CROMOX, y mediante el análisis cualitativo de las imágenes tridimensionales y de color obtenidos por el programa de ODR.

\section{Material y método}

Ocho cerdos Large White (tres machos castrados y cinco hembras) fueron distribuidos en cuatro grupos de dos animales, respectivamente, para los períodos de estudio de 7, 28, 60 y 90 días.
Para preinducción anestésica se empleó acepromacina, 10 $\mathrm{mg} / \mathrm{ml}$ (0,5 mg/kg), más morfina, $10 \mathrm{mg} / \mathrm{ml}$ (0,5 mg/kg), y para la anestesia, clorhidrato de ketamina, $1 \mathrm{~g} / 10 \mathrm{ml}(20 \mathrm{mg} / \mathrm{kg}$ intramuscular), más diazepam, $5 \mathrm{mg} / \mathrm{ml}$ (1 mg/kg) y anestesia de infiltración local de clorhidrato de prilocaína al 3\% con felipresina, 0,03 U/ml.

Se realizó una incisión quirúrgica extraoral en el ángulo mandibular derecho de cada animal para exponer la mandíbula, y después dos cavidades alargadas, homogéneas, con Carbide Drills (número 8 para la alta velocidad y baja velocidad, esférica, con un diámetro de $2 \mathrm{~mm}$ ) en las proporciones aproximadas de $2 \mathrm{~mm}$ de ancho y $4 \mathrm{~mm}$ de profundidad, con una distancia de aproximadamente $7 \mathrm{~mm}$ entre una y otra. Una cavidad se realizó con la alta velocidad (300.000 rpm), y la otra con baja velocidad (20.000 rpm), ambos con el irrigación de solución salina. Se colocó un tornillo de níquel titanio cerca de la cavidad hecha con alta velocidad para facilitar las observaciones posteriores (fig. 1). La sutura fue hecha con puntos interrumpidos, y para controlar el dolor y la hinchazón se aplicó fenilbutazona de sodio y gentamicina profiláctica durante 3 días.

Al final del período de experimento para cada grupo, los animales fueron sacrificados por inyección intravenosa de tiopental y cloruro de potasio. Se apartaron las mandíbulas, se limpiaron de los tejidos blandos y se radiografiaron en la región de las cavidades con películas extraorales, periapicales convencionales y con placas del sistema óptico Digora (Soredex, Corporation Orion, Helsinki, Finlandia) hechas con máquina de rayos X GE-100 (General Electric, Milwaukee, EE.UU.) que funciona a $70 \mathrm{kVp}, 10 \mathrm{~mA}, 12$ impulsos; las películas extraorales procedieron del equipo de GE (General Electric, Milwaukee, EE.UU.), que opera a $50 \mathrm{kVp}, 10 \mathrm{~mA}, 1 / 5$ segundos.

A lo largo de la región en estudio, cada pieza fue colocada junto a una escalera de aluminio (10 pasos) y fotografiada 


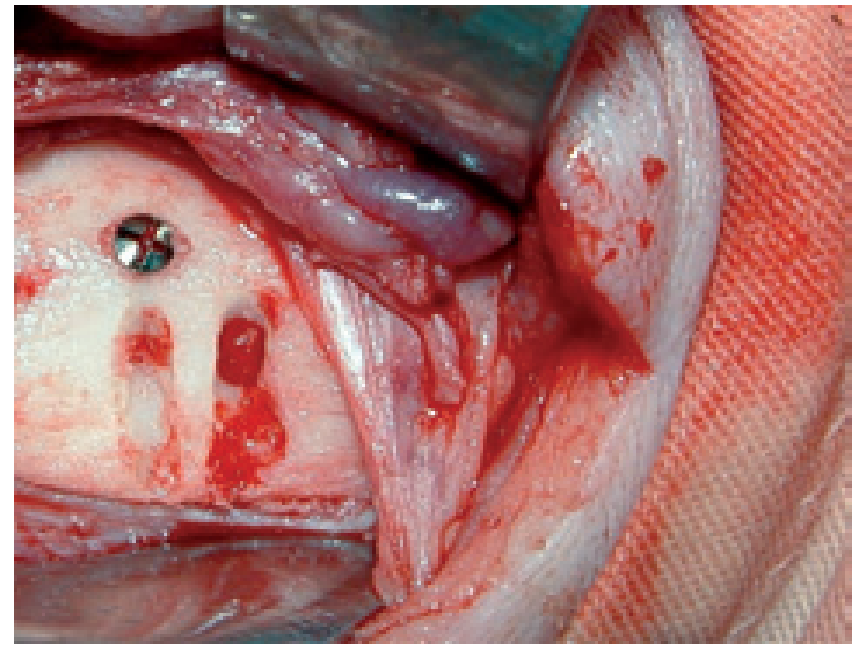

Figura 1 - Osteotomías realizadas con alta velocidad de rotación (marcada por el tornillo) y baja velocidad de rotación.

junto con radiografías periapicales y una cuña de aluminio, fotografiadas con películas extraorales que sirvieron de referencia para la densidad óptica. Las radiografías periapicales convencionales fueron digitalizadas por un escáner convencional, las imágenes se almacenaron en el ordenador mediante el programa informático CROMOX (desarrollado por Advanced Athena-SIA/Sistema de Inteligencia, SJC-SP), y fueron recuperadas para proceder a la lectura de la densidad óptica con valores expresados en niveles de gris. En las osteotomías se realizaron cinco lecturas por área, con un total de veinte lecturas por radiografía (5 medidas en cortical con alta rotación, 5 con baja rotación, 5 en la medular con alta rotación y 5 con baja rotación), además de leer los valores de los pasos de la referencia. Los valores de densidad de todas las imágenes comparadas con la escalera de aluminio se convirtieron en valores equivalentes en el espesor de aluminio a través de una ecuación matemática y del programa de computadora de Louzada et $\mathrm{al}^{7}$. Se realizaron lecturas de las placas sensibilizadas del sistema óptico Digora y de las imágenes mostradas en el software Digora Windows 1.51, lo que permitió la visualización de la reparación ósea cuantitativamente de cada animal por medio de la escala de grises de los píxeles. Para obtener estos valores también se llevaron a cabo cinco medidas de cada área de estudio y de la escala de grises. Con estos valores se obtuvo un promedio por radiografía de cada animal y, por lo tanto, los niveles finales del promedio de color gris en las osteotomías por grupo de animales.

Las imágenes radiográficas de cada hemimandíbula y cuña de aluminio en las películas extraorales fueron digitalizadas y almacenadas con la extensión TIFF. El programa ODR, en desarrollo, escrito en el programa de análisis numérico MAT$\mathrm{LAB}^{8}$, trabajó las imágenes escaneadas de los rayos X y ofreció nuevas imágenes tridimensionales y de color que representaban el grueso de la cuña de aluminio, siendo que los ejes $\mathrm{X}$ e Y de la ubicación de las imágenes en tres dimensiones eran superficiales de los elementos originalmente escaneadas de la imagen y el eje $\mathrm{Z}$ los valores de densidad, expresada en milímetros de aluminio.
Tabla 1 - Estadística descriptiva (media) de los datos obtenidos por el programa Cromox en milímetros de aluminio evaluados por el instrumento utilizado en la osteotomía, la localización y diferentes tiempos del sacrificio

\begin{tabular}{lcccc}
\hline \multirow{2}{*}{ Tiempo (días) } & \multicolumn{2}{c}{ Alta rotación } & \multicolumn{2}{c}{ Baja rotación } \\
\cline { 2 - 5 } & Cortical & Medular & Cortical & Medular \\
\hline 07 & 4,04 & 2,44 & 3,80 & 2,73 \\
28 & 5,16 & 3,23 & 4,34 & 2,51 \\
60 & 4,38 & 2,90 & 5,40 & 3,64 \\
90 & 5,84 & 4,80 & 6,31 & 5,96 \\
\hline
\end{tabular}

\section{Resultados}

Los valores medios de la lectura de la densidad obtenida por medio del programa CROMOX mostró la formación de hueso nuevo medido en números absolutos en los tiempos (tabla 1), donde observamos que la lectura de densidad media en milímetros de aluminio en las osteotomías realizadas con alta rotación en grupos de 7 y 28 días fueron ligeramente superiores a la osteotomía realizada con baja rotación, con la excepción de que en 7 días la densidad ósea en la osteotomía hecha con baja rotación en la región medular se mostró ligeramente superior. En tiempos de 60 a 90 días los resultados mostraron que la mayor densidad en las osteotomías se realizó con baja rotación.

Con el programa Digora se obtuvieron datos sobre el nivel de gris promedio de píxeles en cada región analizada de la osteotomía en la radiografía digital directa, y los resultados fueron iguales a los obtenidos por el CROMOX (fig. 2).

Las osteotomías analizadas cualitativamente por el programa de ODR resultaron en imágenes en tres dimensiones coloridas de cada animal (figs. 3-8), donde en las figuras 3 y 4 podemos ver claramente los ámbitos de las osteotomías (pozos azules), y la discontinuidad de la cortical ósea es representada por el color verde. Siete días después de la cirugía no hubo diferencias visuales en el color entre los pozos hechos con alta rotación y las cavidades realizadas con baja rotación en la corteza y en la medular, ambas presentadas con un color que oscila entre 3 y 4 en la representación de referencia (la cuña de aluminio).

En las figuras 5 y 6, a los 28 días del postoperatorio, ya no se observan las cavidades de las osteotomías, y no hay diferencias entre las regiones en que las osteotomías se realizaron tanto con velocidad alta cuanto con baja. Así como en las figuras 7 y 8 , a los 60 y 90 días después de la cirugía, respectivamente, la curación del hueso parece completa. Además, se observó que la ubicación de las osteotomías con baja rotación en los dos períodos en la medular y la corteza tuvieron una densidad más alta, con el color que representa el espesor de la estructura de cuña, que va desde 5 a 6 (a 60 días) y 6 a 7 (a 90 días), en comparación con los lugares donde la osteotomía se realizó a alta velocidad.

La proyección en color rojo fuerte en las imágenes corresponde a los tornillos por encima de la cavidad hecha con alta rotación. 


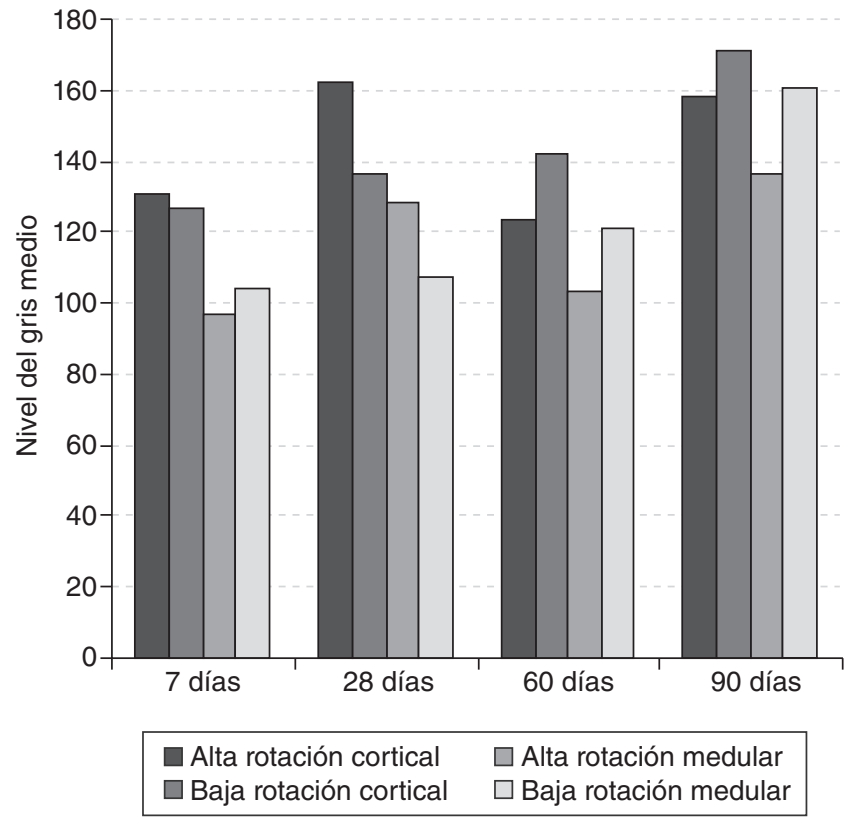

Figura 2 - Valores medios de niveles de gris obtenidos en la radiografía digital directa (Digora) según el tiempo y los tipos de instrumentos rotatorios en las regiones cortical y medular ósea.

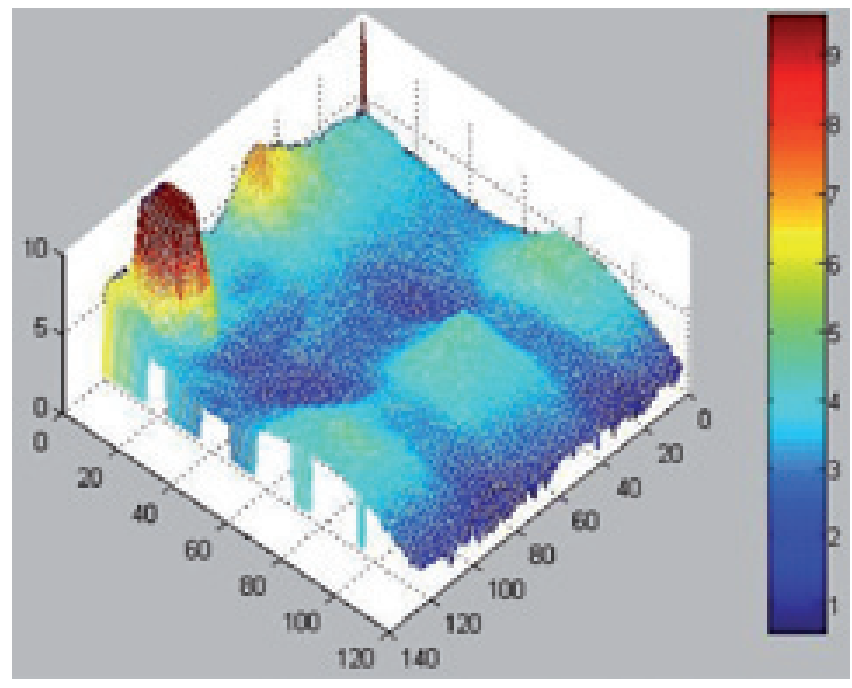

Figura 3 - Imagen tridimensional de la reparación ósea en un animal 7 días después de la cirugía.

\section{Discusión}

La reparación ósea (formación de tejido osteoide y mineralización) es radiográficamente expresada en un aumento de la opacidad a la radiación, y el aumento de densidad óptica ósea de la imagen ${ }^{9}$, dependiendo de la técnica, pues en el CROMOX los valores más altos representan densidades más bajas, y en el Digora cuanto mayor es el valor, mayor es la densidad. Así, el resultado de los análisis densitométricos alcanzados por el CROMOX en tiempo de espera de 7 días fue de mayor densi-

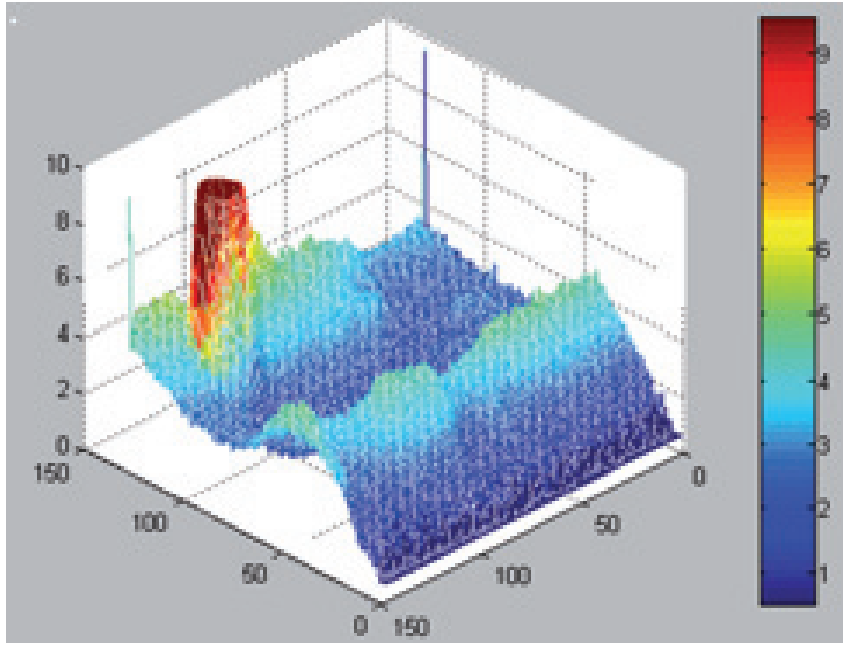

Figura 4 - Imagen tridimensional de la reparación ósea en otro animal 7 días después de la cirugía.

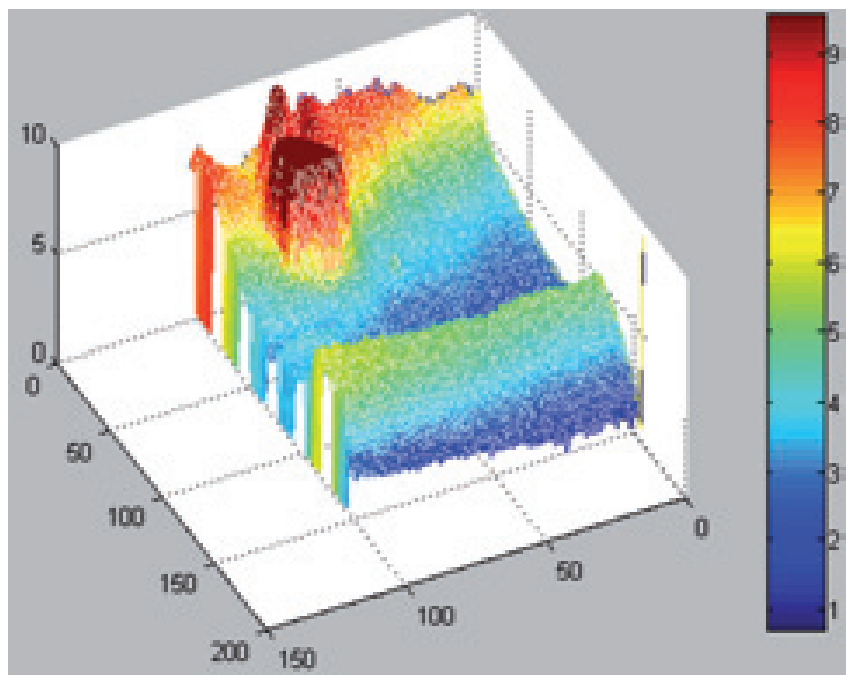

Figura 5 - Imagen tridimensional de la reparación ósea en un animal 28 días después de la cirugía.

dad ósea en milímetros de aluminio en la región del hueso cortical, lo que sugiere una mejor reparación ósea con el uso de la alta velocidad, un resultado ya confirmado por los estudios de Toledo ${ }^{2}$, en observación histológica de la reparación ósea en las zonas con osteotomía de alta rotación e irrigación, donde al mismo tiempo se obtuvo la presencia de tejido ricamente celular que llenaba todo el hueco y cerraba el hueso trabecular maduro preexistente. Sin embargo, en la región medular la densidad ósea en milímetros de aluminio fue ligeramente superior en los dos animales sometidos a osteotomías de baja velocidad, y el mismo resultado también se observó cuando se realizó el análisis de los niveles promedio de gris de los píxeles obtenidos por el Digora. Esto puede ser controvertido como consecuencia de la falta de normalización de la presión durante las osteotomías, por lo que, al ser la medular menos mineralizada que la corteza, la presión ejercida por la alta velocidad podría haber causado un corte 


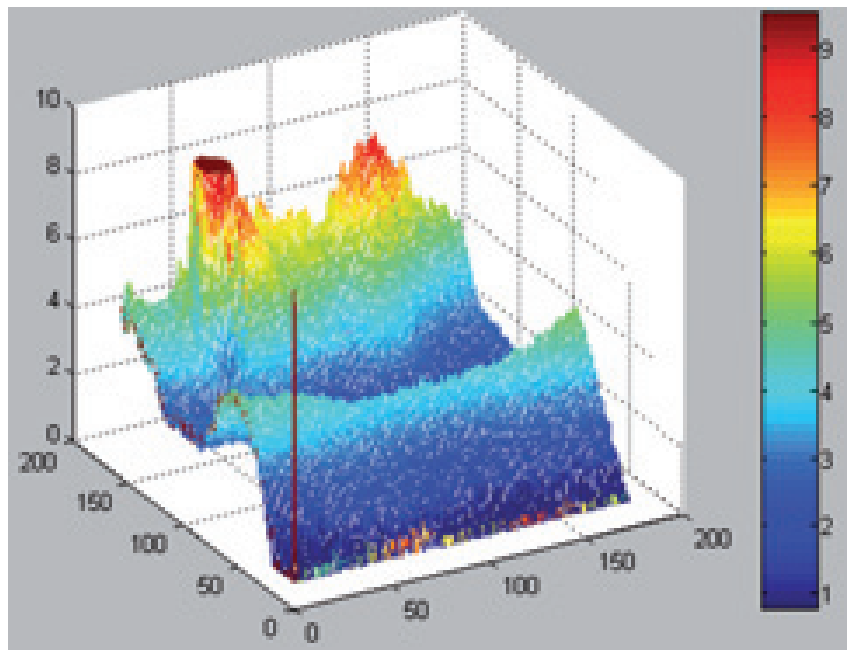

Figura 6 - Imagen tridimensional de la reparación ósea en un otro animal 28 días después de la cirugía.

profundo, que podría ser la causa de la mayor densidad de 7 días en las osteotomías realizadas con baja rotación.

En el tiempo postoperatorio de 28 días, los valores de la densidad obtenidos a través del CROMOX y del DIGORA en las zonas con osteotomías hechas con alta rotación tanto en la corteza como en la medular fueron más grandes, lo que contradice los resultados obtenidos por Toledo et $\mathrm{al}^{2}$, que en el mismo tiempo postoperatorio mostraron una mejor cicatrización del hueso en osteotomías a baja velocidad y refrigeración líquida.

Ya en tiempos de 60 a 90 días, los resultados mostraron mayores densidades en osteotomías realizadas con baja rotación, lo mismo que observaron Pereira et $\mathrm{al}^{10}$.

Costich et $\mathrm{l}^{11}$ realizaron un estudio comparativo de la osteotomía en perros utilizando las velocidades altas y bajas, con y sin refrigeración en los períodos postoperatorio de menos de 8 semanas, y consiguieron mejores resultados de reparación con el uso de la alta velocidad, tal vez por producir menos calor, ya que en tiempos mayores las diferencias no fueron significativas, pero muchos autores muestran siempre mejores resultados con la alta rotación ${ }^{1,12,13}$.

En 1965, Hall ${ }^{14}$, en una evaluación de la reparación ósea en el conejillo de Indias, observó una reparación ósea completa dentro de los 30 días después de la cirugía, con resultados similares tanto para la alta como para la baja velocidad.

Con respecto a las diferencias morfológicas e histológicas entre el hueso de cerdo y humano, muchos autores ${ }^{15-17}$ relataron que tanto la densidad como el metabolismo óseo son similares, un hecho que ha estimulado nuevos estudios de la densidad ósea en los cerdos, como los realizados por Robertson et $\mathrm{al}^{18}$, que evaluaron densitométricamente el proceso de cicatrización de la mandíbula de cerdos después de la osteotomía; por Christgau et $\mathrm{al}^{19}$, que utilizaron los rayos $\mathrm{X}$ por sustracción digital para encontrar los cambios cuantitativos en la densidad y los cambios en la masa de calcio en mandíbula; por Holtzhauer et $\mathrm{al}^{20}$, que estudiaron la densidad ósea radiográfica de los defectos de distracción osteogénica, y por Trento $^{21}$, que estudió la densidad ósea en la mandíbula de los

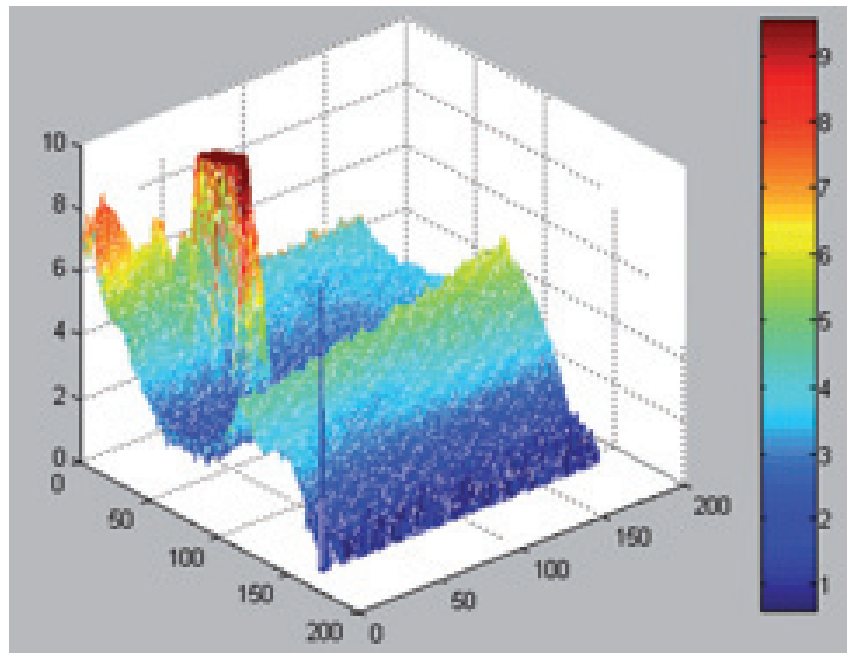

Figura 7 - Imagen tridimensional de la reparación ósea en un animal 60 días después de la cirugía.

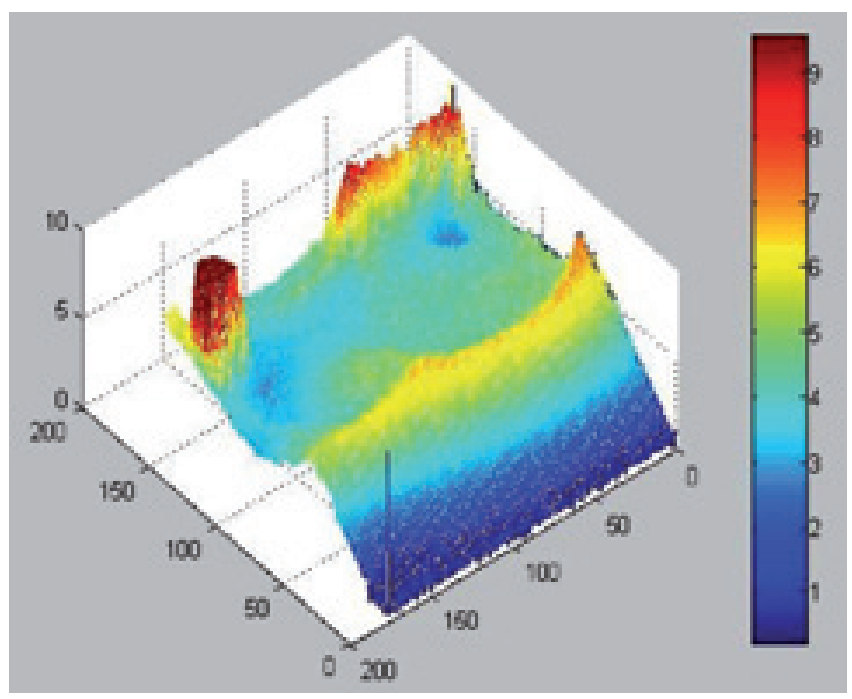

Figura 8 - Imagen tridimensional de la reparación ósea en un animal 90 días después de la cirugía.

cerdos sometidos a un injerto de hueso autógeno, homogéneos y heterogéneos.

Este estudio utilizó cerdos de aproximadamente 3 meses en que el factor hormonal no tenía importancia, ya que se sabe que hay diferencias en densidades óseas debido a acción hormonal en machos y hembras ${ }^{16,22}$, y además no se hizo la comparación entre los animales, pero sí la comparación entre los pozos en el mismo animal.

La evaluación cuantitativa del proceso de reparación ósea mediante la comparación de los dos métodos de osteotomía demostró ser rápido, sencillo y de bajo coste. Los errores inherentes a la falta de estandarización de la densitometría pueden superarse cuando se utiliza una escalera de aluminio, fotografiado al mismo tiempo para estudiar los materiales, una vez que para todas las variaciones que podrían ocurrir, también las referencias se quedarían afectadas ${ }^{8,23}$. 
El programa ODR que transforma las imágenes escaneadas de las radiografías en nuevas imágenes tridimensionales y de color mostró que las ubicaciones de las osteotomías 7 días después de la operación eran claramente visibles, pero en los 28, 60 a 90 días no fue posible observar defectos óseos; por lo menos, al parecer, la reparación estaba completa, aunque Robertson et $\mathrm{l}^{18}$ consideraron la necesidad de un mayor tiempo (hasta 12 semanas) para la restauración de la densidad normal en su estudio en las mandíbulas de cerdo. En ODR, la presentación de la densidad óptica en color hace posible una mejor visualización y la evaluación cualitativa de los niveles de densidad mineral ósea. En las imágenes en color se hicieron comparaciones cualitativas entre la región de osteotomías y las regiones adyacentes en conserva, que sirvieron como referencia visual del estado evolutivo del proceso de curación del hueso.

\section{Conclusión}

En tiempos más recientes, la densidad más alta se produjo en las osteotomías realizadas con alta velocidad con refrigeración, excepto durante 7 días en la medular, en que la reparación fue mejor con la baja velocidad; en tiempos más largos, la densidad fue mayor en las osteotomías realizadas con baja rotación y refrigeración líquida.

A pesar del alto coste, el modelo biológico cerdo es perfectamente adecuado para el estudio de la reparación ósea por densitometría.

\section{B I B L I O G R A F Í A}

1. Okamoto T, Yamamoto ME, Sonoda CK. Processo de reparação óssea após osteotomia com instrumentos rotatórios de alta rotação: estudo histológico em cães após emprego de dois tipos de broca com e sem resfriamento. Rev. Brás Odontol. 1994;51:21-5.

2. Toledo HJB. Osteotomia com brocas de alta e baixa rotação, com e sem refrigeração líquida: estudo histopatológico duplo cego em suínos. [Disertación de Maestro.] Araçatuba: Universidad Estadual Paulista; 2004. 84 p.

3. Scarparo HC. The presentation of a exploratory method to analyse mandible osseous density. [Disertación de Maestro.] Porto Alegre: Pontifícia Universidade Católica do Rio Grande do Sul; 1995.

4. Benlidayi ME, Gaggl A, Buerger H, Kürkcü M, Unlügenç H, Onal $\mathrm{D}$, et al. Comparison of vascularized osteoperiosteal femur flaps and nonvascularized femur grafts for reconstruction of mandibular defects: an experimental study. J Oral Maxillofac Surg. 2009;67:1174-83.

5. Louzada MJQ. Microdensitometria em radiografias de perfurações ósseas. [Disertación de Maestro.] Ribeirão Preto: Facultad de Medicina de Ribeirão Preto-USP; 1988.

6. Louzada MJQ. Otimização da técnica de densitometria óptica em imagens radiográficas de peças ósseas. Estudo in vitro.
[Tesis doctoral.] Campinas: Facultad de Ingeniería EléctricaUNICAMP; 1994.

7. Louzada MJQ, Pelá CA, Belangero WD, Santos-Pinto, R. Avaliação de densidade óssea em imagens radiográficas: estudo em peças ósseas de cães. RBE: Rev Bras Eng Cad Eng Biomed. 1998;14:47-64.

8. Pelissoni LGR, Louzada MJQ Silva AM, Martins LEB, Belangero WD. Influence of ketoprofen on ulnar osteotomy healing in rabbits: qualitative and quantitative study using image analysis softwares. Acta Cir Bras [ed. electrónica]. 2003 [citado el 20 enero 2005], set-oct;18(5). Disponible en: http://www. scielo.br/scielo.php?script=sci_arttext\&pid=S0102-8650200300 0500011

9. Bodner L, Kaffe I, Littner MM, Cohen J. Extraction site healing in rats. A radiologic densitometric study. Oral Surg. Oral Med. Oral Pathol. 1993;75:367-72.

10. Pereira JA, Carvalho ACP, Okamoto T. Osteotomy with rnicromotor and high speed rotatory instruments in dog mandibles: comparative histological study. Rev Odontol UNESP. 1996;25:9-18.

11. Costich ER, Youngblood PJ, Walden JM. A study of the effects of high-speed rotary instruments on bone repair in dogs. Oral Surg. Oral Med. Oral Pathol. 1964;17:563-71.

12. Iyer S, Weiss C, Mehta A. Effects of drill speed on heat production and the rate and quality of bone formation in dental implant osteotomies. Part II: Relationship between drill speed and healing. Int. J. Prosthodont. 1997;10:536-40.

13. Sharawy M, Misch CE, Weller N, Tehemar S. Heat generation during implant drilling: the significance of motor speed. J Oral Maxillofac Surg. 2002;60:1160-9.

14. Hall RM. The effect of high-speed bone cutting without the use of water coolant. Oral Surg. Oral Med. Oral Pathol. 1965;20:150-3.

15. Atkinson PJ. Changes in resorption spaces in femoral cortical bone with age. J Pathol Bacteriol. 1965;89:173-8.

16. Powell K, Atkinson PJ, Woodhead C. Cortical bone structure of the pig mandible. Arch Oral Biol. 1973;18:171-80.

17. Troulis M, Glowacki J, Perrott DH, Kaban LB. Effects of latency and rate on bone formation in a porcine mandibular distraction model. J Oral Maxillofac Surg. 2000;58:507-13.

18. Robertson DM, Smith DC, Das SK, Kumar A. Microdensitometry as a clinical tool for diagnosing the progress of fracture healing. J. Oral Surg. 1980;38:740-3.

19. Christgau M, Hiller KA, Schmalz G, Kolbeck C, Wenzel A. Accuracy of quantitative digital subtraction radiography for determining changes in calcium mass in mandibular bone: an in vitro study. J Periodontal Res. 1998;33:138-49.

20. Holtzhauer DP, Larsen PE, Miloro M, Vig KW. Distraction osteogenesis of the mandible with a modified intraoral appliance: a pilot study in miniature pigs. Int J Adult Orthodon Orthognath Surg. 1998;13:241-7.

21. Trento CL. Bony densitometry in jaw of swine submitted to autogenous, homogenous and heterogenous bone graft. [Tesis doctoral.] Araçatuba: Universidad Estadual Paulista; 2006.

22. Inui $A$, Itamoto $K$, Takuma $T$, Tsutsumi $H$, Tanigawa $M$, Hayasaki $\mathrm{M}$, et al. Age-related changes of bone mineral density and microarchitecture in miniature pigs. JVet Med Sci. 2004;66:599609.

23. Jeffcoat MK, Jeffcoat RL, Willians RC. A new method for the comparison of bone loss measurements on non-standardized radiographs. J Periodontal Res. 1984;19:434-40. 